\title{
Estimating the willingness to pay for the purchase of pasteurized milk in Faisalabad, Pakistan
}

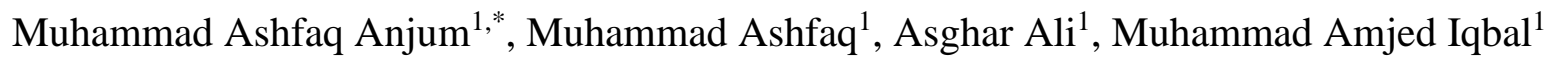 \\ and Muhammad Ilyas ${ }^{1,2}$ \\ ${ }^{1}$ Institute of Agricultural and Resource Economics, University of Agriculture Faisalabad, Pakistan; ${ }^{2}$ Assistant Professor, \\ Government Graduate College Samanabad Faisalabad, Pakistan \\ "Corresponding author's e-mail: asghar.ali@uaf.edu.pk
}

\begin{abstract}
Milk is a vital constituent of the human diet. It is a rich source of high biological value protein and essential minerals like calcium, phosphorus and potassium. It has protective effects against many acute and chronic diseases. Milk gives comparatively rapid returns to small scale livestock keepers. Huge quantity of milk is produced by small farmers in developing countries like Pakistan and it is expected that demand for milk will increase by 25 percent by 2025 . Pakistan is the world's fifthlargest producer of milk and produces about 60 million metric ton of milk in a year. Only 6 percent of milk is being pasteurized. Livestock sector in Pakistan contributes 11.10 percent to Gross Domestic Product (GDP). Approximately 35 million households in rural areas are associated with the profession of dairy industry in Pakistan. Pasteurized milk is much better than raw milk because pasteurization is a preventive measure of public health significance as it makes the milk safe for human use. The main objective of this study was to find out the willingness to pay by consumers for the purchase of pasteurized milk. In this regard, interviews were conducted from 150 households during May, 2020 from 3 localities namely Ghulam Muhammad Abad, Muhammad Pura and Marzi Pura in Jinnah town District Faisalabad. Binary logistic model was applied to explore variation in various measures of the respondents' willingness to pay. The results of the model revealed that factors like income, education, expenses on milk, number of children and milk source were found significant for willingness to pay. Further, household is spending on an average $11 \%$ of his income on milk consumption and is willing to pay Rs. 7.5 per liter for pasteurized milk. These findings have essential implications for policy makers.
\end{abstract}

Keywords: Willingness to pay, pasteurization, income groups, contingent valuation method.

\section{INTRODUCTION}

Milk is consumed worldwide as it is considered a vital food. Milk is a good source of calcium, vitamins, minerals (phosphorus and calcium) and other nutrients. People of all ages consume milk and its products in their daily life that depends upon the availability and income etc. Huge quantity of milk is produced by the small farmers in developing countries and it is expected that the world demand for milk will increase by 25 percent by 2025 (FAO, 2018). Livestock sector in Pakistan contributes 11.10 percent to Gross Domestic Product (GDP). Approximately 35 million households in rural areas are associated with the profession of dairy industry. Pakistan is the world's fifth largest nation in production of milk and produces about 60 million metric ton of milk in a year. Only about 6 percent of milk is pasteurized (GOP, 2019).

Livestock sector provides food, income and jobs to the people as well as encourages the farmers/stakeholders and food suppliers by providing guidance. The demand regarding products of livestock is increasing rapidly in the developing countries. Farmers and suppliers associated with dairy sector get quick returns. Huge quantity of milk is produced by the small farmers in the developing countries. It was examined that about 80 percent of milk was handled by informal ways with inadequate regulations (Tanvir, 2007).

The role of Punjab province in the economy of Pakistan is appreciated due to its flourishing livestock sector that is important for the wellbeing of the majority of households in rural Punjab (Ashfaq et al., 2015). Punjab Livestock and Dairy Development Board (PLDDB) is struggling to provide pure, hygienic safe milk to consumers focused on no profit and no loss. It provides delicious whole milk for customers, full of nutrients. It pure Sahiwal cow milk from its own farm located in Khizerabad, Sargodha and processed it in its own pasteurization and chilling plant in accordance with

Anjum, M. A. A, M. Ashfaq, A. Ali, M. A. Iqbal and M. Ilyas. 2021. Estimating the willingness to pay for the purchase of pasteurized milk in Faisalabad Pakistan. Pak. J. Agri. Sci. 58:1405-1410.

[Received 29 Sep 2021; Accepted 8 Jun 2021; Published (online) 21 Sep 2021]

(c) (1) 
international standards and then shipped to Lahore via chiller van milk is finally delivered to end consumers via automatic milk selling machine in sealed packaging (PLDDB, 2020).

The consumers are price conscious in Pakistan because their income is low and prices of products are increasing. Therefore, demand for the consumption of raw milk is different from region to region as compared to processed/pasteurized milk (Zia, 2016). Raw milk is supplied from dairy farms to the residential localities and markets directly. This type of delivery channels favors the milk suppliers and consumers to avoid sale fees/taxes to the Government. Raw milk that is delivered to milk users not have any safety control. Developing countries consume raw milk more as compared to developed countries (Vinolaet al., 2018).

Dairy sector in Pakistan has been facing many challenges. Production system and large-scale processing facilities are two major sources of environmental degradation of dairy sector in Pakistan. There is inefficient market mechanism and low profitability to dairy farmers as compared to other industries. Farms are usually segregated and not managed properly despite the potentiality is available in the regions. The majority of farmers and milk suppliers/milkmen are illiterate or less educated. They do not care their consumers regarding the supply of pure milk. The milkmen add starch in the milk to make it thick that might be harmful for the health of the consumers. Rules and regulations have been set by the Government of Pakistan regarding pasteurization of milk and its supply to consumers (Tanveer, 2015).

Commonly milk is not treated hygienically. Milk that contains dust, dirt, high bacteria count, foreign materials, and with off flavor is contaminated milk. Due to this contamination, food borne pathogens grow into the milk that causes food borne illness like nausea, fever, dehydration, cholera, vomiting, abdominal cramps and syndrome. Microbes enter into the milk by different sources such as bared handed use or no use of glove, milk collection in the contaminated utensils, not sterilized instruments, air contamination, improper storage, improper handling, and animal may be under diseased (Siddique, 2018).

The US Public Health Service established model legislation called the "Pasteurized Milk Ordinance" to be jointly implemented by the state and local governments (Angulo et al 2009). Milk is pasteurized through Vat (batch) pasteurization (63 C for 30 minutes); HTST (72C for 15 seconds); HHST(89- $100 \mathrm{C}$ for 1.0-0.01 seconds) with shorter shelf life (Mariam, 2020).

The Chairman, Punjab Food Authority (PFA) decided to ban sale of open/raw milk in Punjab Province with effect from 2022 and asked to the concerned staff to provide awareness to the milk consumers and small farmers about pasteurized milk. The Punjab Food Authority (PFA) was committed to ensure that all consumers would be able to get safe milk supply. Pakistan has more animals, goats and sheep than Turkey, but milk is not up to standards (PFA, 2019).The process of milk pasteurization not only kills the pathogens but also improves the health safety and increases the shelf life of milk. Pasteurized milk is preferred in the world especially in the developed countries due to its health benefits. There is a ban on sale of raw milk in many countries. They declared that sale of unpasteurized milk is illegal (Butt, 2019).The World Health Organization declared that corona virus is pandemic disease. It may cause illness of birds, mammals and in humans through respiratory tract infections, so people should not consume raw food in current scenario of Covid-19 (HEC, 2020).

Keeping in view the past studies, it has been learnt that consumption of pasteurized milk is more fruitful for health as compared to raw milk so this study was designed to estimate the willingness to pay by the consumers for the pasteurized milk. The objectives of this study are: 1) to study the socioeconomic characteristics of respondents, 2) to estimate the willingness to pay of consumers for the pasteurized milk and 3 ) to suggest appropriate policy measures regarding the present system of milk market. Rest of the study is organized as follows. Section II presents the methods of analysis. Section III contains analysis and discussion of the results. Final section IV concludes the study.

\section{MATERIALS AND METHODS}

Faisalabad is the $3^{\text {rd }}$ most populous city of Pakistan. It has been divided into eight towns namely; Lyallpur Town, Madina Town, Jinnah Town, Iqbal Town, ChakJhumra Town, Jaranwala Town, Samundri Town and Tandlianwala Town. This study was conducted in Jinnah Town which is the totally urban area with heterogeneous demographic and socio economic characteristics. The study area is not only thickly populated but population is ever increasing which is creating many opportunities and problems. Milk is a basic food item is being consumed by each household in some form and quantity.

Conceptual Framework: The conceptual framework describes the study direction. It develops to make research results more concrete, appropriate in the field of science. A conceptual framework is a way to provide the structure of the study (Adom et al, 2018). It explains how the concerned variables are relating to each other. The current study is dealing with consumer's willingness for the pasteurized milk. A random sampling technique was used for the selection of sample. The data were collected from 3 localities namely Marzi Pura, Muhammad Pura and Ghulam Muhammad Abad from 150 respondents through personal contact and interview using a comprehensive questionnaire. Out of 150 respondents, 50 were each from low income, medium income and high income households. After making necessary corrections and modifications, the developed questionnaire was pre-tested 


\section{Determinants of pasteurized milk}

before collecting the required information from study area. SPSS (version 22) was used for data analysis.

To evaluate the consumer's willingness to pay for pasteurized milk. The different approaches were used to estimate the willingness to pay for pasteurized milk: productivity changes method, and contingent valuation methods. Most commonly contingent valuation method was used to estimate the consumer willingness to pay (Papke and Wooldridge, 1996). A contingent valuation (CVM) approach was used to evaluate the consumers' response in the absence of a real purchasing scenario. The CVM approach allows a direct estimation of willingness to pay (WTP) by means of different elicitation techniques (Alberini and Cooper, 2000). The payment cards were used to estimate the WTP with a minimum of Rs. 0 and maximum of Rs. 20.Binary logistic regression is used to predict the odds of being a case based on the values of the independent variables (predictors). The odds are defined as the probability that a particular outcome is a case divided by the probability that it is a non-case.

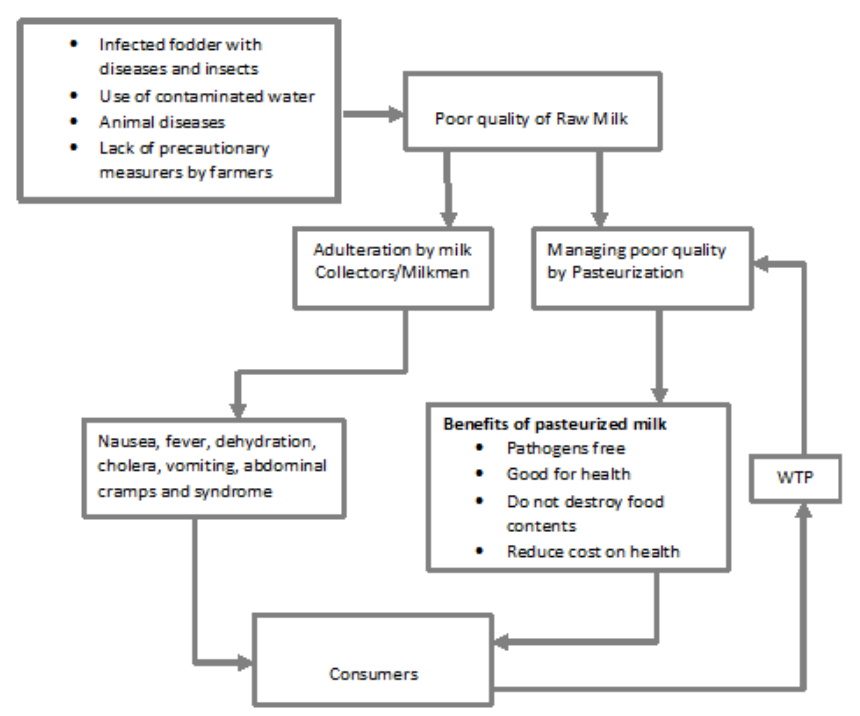

Source: Authors' Own Drawing

\section{Figure: Conceptual Frame work}

Binary logistic model for this study indicated as: $\mathrm{P}_{1}$

$$
\frac{P_{1}}{\left(1-P_{1}\right)}=\frac{1+\exp \left(Z_{1}\right)}{1+\exp \left(-Z_{1}\right)}
$$

Where $\mathrm{P}_{1} /\left(1-\mathrm{P}_{1}\right)$ is the ratio of the probability that consumers will be willing to pay for pasteurized milk to the probability that consumers will not be willing to pay. So the dependent variables are binary and it has two values 1 and 0 . If a consumer is willing to pay then its value is one and the value is 0 for the consumer who is not willing to pay. As the above equation is non linear, it can be made linear by taking the natural $\log$ then the given model is

$$
\mathrm{L}_{1}=L_{n}\left[\frac{Z_{1}}{1-P_{1}}\right] Z_{1}
$$

The following regression equation is used for dichotomous choice of willingness to pay

$$
\begin{gathered}
Y=\beta_{0}+\beta_{1} X_{1}+\beta_{2} X_{2}+\beta_{3} X_{3}+\beta_{4} X_{4}+\beta_{5} X_{5}+\beta_{6} X_{6} \\
+\beta_{7} X_{7+} e_{i}
\end{gathered}
$$

$\mathrm{Y}$ is willingness to pay (dichotomous) variable, $\mathrm{X}_{\mathrm{i}}$ 's are independent variables including gender, income, education, expenses on milk, awareness, number of children and milk source. $\beta_{0}$ is the intercept and $\beta_{i}$ 's are the coefficients of estimators and $e_{i}$ is the random error term. $\mathrm{X}_{1}=\operatorname{Gender}(1$ for male and 0 for female), $X_{2}=$ Income (in Rs.), $X_{3}=$ Education (1 for illiterate, 2 for up to 5 years, 3 for up to 10 years, 4 for up to 14 years, 5 for 16 years and above, $\mathrm{X}_{4}=$ Expenditures on Milk per day (1 for up to Rs. 100, 2 for Rs. 101 to Rs. 200, 3 for Rs. 201 to Rs. 300, 4 for Rs. 301 to Rs. 400, 5 for above Rs. $400, \mathrm{X}_{5}=$ Awareness about pasteurized milk ( 1 for yes and 0 for no), $X_{6}=$ Number of children (less than 18 years of age), $X_{7}=$ Milk Source (1 for milkman, 2 for shop, and 3for others)

The data collected through interview schedule mostly depend on households will, so the response may slightly differ from the reality. The results thus reported in this study might be subject to these limitations. The regression coefficients were compared through t-test (Paternoster et al., 1998).

This section interprets the results and tabulates the data collected from respondents. It includes the descriptive statistics of respondents, willingness to pay for pasteurized milk in study area, impact of price on willingness to pay on pasteurized milk and the binary logistic regression results and discussion.

Descriptive Statistic: Descriptive statistic is used to analyze the data. It helps to describe, summarize and show data in a more meaningful way, since trends emerge from data. Descriptive statistic does not give conclusion beyond the data that have been analyzed or reach conclusions regarding any hypothesis might have been made. This is simply a way to describe data. Descriptive statistic is very important because if simple data (raw data) are presented. It is hard to understand what the data are showing specifically if there is a lot of data. Descriptive statistic therefore enables to present the data in more meaningful way on the bases of which simple interpretations of the data are made.

Table 1. Socioeconomic characteristics of respondents.

\begin{tabular}{lrrrr}
\hline Variables & Mean & Min. & Max. & Std. Dev. \\
\hline Age (years) & 39.23 & 18 & 80 & 13.80 \\
Education (Years) & 8.46 & 0 & 18 & 4.49 \\
Household size (No) & 5.97 & 2 & 14 & 2.08 \\
$\begin{array}{l}\text { Income (in thousands } \\
\text { Rs./month) }\end{array}$ & 60.40 & 15 & 200 & 39.90 \\
$\begin{array}{l}\text { Expenses on Milk (per } \\
\text { day) Rs. }\end{array}$ & 223.00 & 80 & 560 & 106.50 \\
$\begin{array}{l}\text { Awareness about } \\
\text { pasteurized milk }\end{array}$ & 0.41 & 0 & 1 & 0.49 \\
$\begin{array}{l}\text { WTP for Pasteurized } \\
\text { Milk Rs./liter }\end{array}$ & 7.56 & 5 & 20 & 1.18 \\
\hline Source: Authors Own Calculations & & &
\end{tabular}


A number of questions were asked in relation to the socioeconomic characteristics of the respondents. Information about respondent's profile included their age, gender, income, education level, household size, marital status and expenses on milk. Income, education and household size were expected to have important factors of willingness to pay of respondents. According to Table 1, mean value of age was 39.23 years. Minimum age was 18 years and maximum of 80 years showing that all respondents were adults. Mean value of education was 8.46 years. The minimum education was 0 years showing the respondents were illiterate. The maximum education was 18 years showing the respondents were higher educated. The mean household's size was 5.97. Minimum households size was 2 and maximum 14 members consisting of a household that shows that mean family size is close to the Punjab estimates which was 6.3 according to the Punjab Bureau of Statistics (2018) and mean value of income was 60443.33 rupees per month. The minimum income was found 15000 in Marzi Pura and Maximum 200000 in Ghulam Muhammad Abad. The per month mean expenditure on milk was Rs. 6640.8 showed that a mean household was spending about 11 percent of his income only on milk. The mean value of expenses on milk was 223 rupees per day; its minimum value was Rs. 80 that shows that milk is essential part of our daily food ad no family was found that was not using milk. The maximum amount of rupees 560 was spending on the purchase of milk. The mean value of awareness was 0.41 or 41 percent; it means that only 41 percent of the respondents were aware about pasteurized milk and remaining 59 percent showed their ignorance. The main cause of relatively low response is lack of education and information of the respondents. The mean value of paying for pasteurized milk was 7.56 which mean that people are willing to pay more for the purchase of pasteurized milk instead of raw milk.

Table 2. Logistic regression results for willingness to pay for pasteurized milk.

\begin{tabular}{lccc}
\hline Variables & $\boldsymbol{\beta}$ & Sign & $\operatorname{Exp~(\beta )}$ \\
\hline Gender (male or female) & 0.287 & 0.565 & 1.332 \\
Income (in thousands) & $0.060^{* * *}$ & 0.003 & 1.240 \\
Education (in years) & $0.372^{* * *}$ & 0.000 & 1.450 \\
Expenses on milk (in rupees) & $-0.009^{* * *}$ & 0.004 & 0.991 \\
Awareness (yes or no) & $1.261^{* *}$ & 0.017 & 3.530 \\
Milk source & 0.320 & 0.337 & 1.378 \\
Constant & -3.852 & 0.003 & 0.021 \\
\hline Model predicted percentage (mpp) & $59.3 \%$ & & \\
Log likelihood ratio & 119.453 \\
Hosmer and lemeshow test & $(d f=8)$ significance test result \\
& $5.323(p$-value=0.723) \\
Cox \& Snell r2 & 0.426 & \\
Negelkerke r2 & 0.575 & \\
Source: Authors Own Calculations & \multicolumn{3}{l}{} \\
*significance at 10\%; **significance at 5\%;**significance at 1\%
\end{tabular}

Table 2 elucidates the results of binary logistic regression, explaining the determinants for milk consumers' willingness to pay for pasteurized milk. The Hosmer and Lemeshow $(\mathrm{H}-$ L) test results show non-significant indicating that the model is good fit. While Cox \& Snell r2 and Negelkerke r2 values are 0.426 and 0.575 which indicates that about 43 to 57 percent variations are explained by the model. The model predictive ability is $59.3 \%$.

The coefficients of the variables do not give the direct information about the effect of changes in explanatory variables on the probability of consumer's willingness to pay. To know this odds ratio/exp ( $\beta$ ) is necessary to determine. This is the ratios of the probability of consumers' willingness to pay to the probability that consumers not willingness to pay. The strongest contributor in willingness to pay was awareness which recorded the highest odds ratio of 3.53 . Awareness is positively affecting willingness to pay. The value of partial coefficient is 1.261 and $\mathrm{p}$ value is 0.017 showing the results are significant at 95 percent. This finding is in line with (Naygaet al., 2006) and (Van et al., 2011).Nutritional awareness was one of the most important components which required more attention, and this would undoubtedly contribute to a positive outcome for dairy products as reported by (Siddique 2018).

The variables which are affecting significantly the probability of willingness to pay are income, education, expenses on milk, and awareness which are changing the probability. However, expenses on milk have negative sign. It means more expenses less probability of willingness to pay. Thus, by increasing income of consumers the share of expenditure on milk with respect to overall expenditures will fall and probability of willingness to pay will increase. The results explain that by increasing the income of consumers' probability of willingness to pay increases by the value of associated odds ratio which is 1.24 . The value of coefficient is very small however it is significant at 99 percent. Education also contributes positively to willingness to pay for the purchase of pasteurized milk. The value of its partial coefficient is 0.372 which shows that increase one level of education increases 0.372 of willingness to pay for pasteurized milk. The results for education are also highly significant at 99 percent level of significance. As for as expenses on milk is concerned the value of its partial coefficient is -0.009 which is negative and showing an inverse relation between expenses on milk and willingness to pay for pasteurized milk. It also shows that as expenses on milk increases by 1 percent the willingness to pay falls by 0.009 percent. The $p$ value is 0.004 showing results significance at 99 percent as coincided with (Amirnejad and Tonakbar 2015). The probability of consumer's willingness to pay increases with gender whose odd ration is 1.332 yet results are statistically insignificant. Sign of gender was positive which shows that males were more willing to pay than females. The 


\section{Determinants of pasteurized milk}

milk source is also affecting the willingness to pay. The value of its partial coefficient is 0.32 which shows that people prefer milk delivery at their home. Yet, results are also insignificant.

Conclusions: Milk is an omnipresent constituent of the human diet. Being a vital source of micro and macro nutrients, it plays important role in human nutrition and development. Hence, the supply of pasteurized milk is crucial for consumers' health. Milk contamination with pathogens is posing risks to human health. The concentration of pathogens above the safe limits in raw milk is not good for growth of children and adult's health. The provision of pasteurized milk may contribute to achieve the Millennium Development Goals (MDGs) by improving human health and eradicating poverty and food insecurity.

This study contributes to the existing literature by investigating consumer's heterogeneous preferences for pasteurized milk. The total population selected for the study was stratified into three strata based on the common characteristics of income such as low income strata (Marzi Pura) medium income strata (Muhammad Pura) and high income strata (Ghulam Muhammad Abad) A discrete choice experiment survey was conducted with a random sample of 150 milk consumers from 3 localities namely Marzipura, Muhammad Pura and Ghulam Muhammad Abad (A Block, B Block and $\mathrm{C}$ Block) in the District Faisalabad. 50 questionnaires were filled from each locality using convenient random sampling approach.

The use of unhealthy food items appears to be a major cause of food borne disease in developing countries such as Pakistan. The worsening health and economic effects of consumption of unhealthy foods could dramatically reduce consumer understanding of how fresh foods are treated safely and improved quality and affordability (e.g., pasteurized milk vs. raw milk). It is important to understand the desires and interests of buyers for such foodstuffs in order to develop an effective strategy for increasing the demand of consumers and to make them safer. However, the treatments related to food safety are subject to increase in costs and then rise in price which makes such products more expensive. This study is an effort to contribute to the insufficient literature on willingness to pay of consumers for significant food product pasteurized milk in Marzipura, Muhammad Pura and Ghulam Muhammad Abad of District Faisalabad. The results explore that consumers have a preference in buying and consuming pasteurized milk if it is available easily and at reasonable price. Traditional preventive measures to kill harmful pathogens are boiling which is adopted by those consumers who use raw milk in their daily life. It was also found that consumers are willing to pay a price premium for pasteurized milk that is higher than average retail price of raw milk. Since consumers are ready to pay extra amount in purchasing safe milk, thus it is necessary to share this valuable information with milk processor so that this positive signal may motivate them for further investment in this sector the increase production will be helpful to maintain prices in extended safe milk. Moreover, previous studies focused on household income and retail prices on demand for dairy products have been considered the key drivers of milk consumption in many countries. However, this study contribute to existing literature by identifying these additional factors such as habits, attitude of consumers, age, gender, education, and number of children are found key indicators that determines demand and preference for safe/pasteurized milk. It is important to take these factors into account while preparing strategies to boost up the demand for pasteurized milk. This study provides new insights into the willingness to pay for pasteurized milk. However, more work on the same topic will use a large range of samples, including various geographical areas, to obtain a more detailed and in-depth understanding of the issue as it affects public health and safety.

Recommendations for enhancing willingness to pay for pasteurized milk: The following recommendations are made on the basis of study findings.

- Many respondents are illiterate or less educated having no information about milk related health problems so education level should be increased.

- Consumers should demand milk suppliers to provide pathogens free milk to ensure health safety.

- Availability of pasteurized milk in surroundings will promote its consumption.

- Purchasing power of consumers should be increased to motivate them to become more health conscious.

- Government should provide information to the consumers because they are anxious to receive more information and assurances about the milk they consume.

\section{REFERENCES}

Amirnejad, H.and P.Tonakbar. 2015. Estimating the Willingness to Pay for Organic Milk Consumption:Case Study of Tehran. J. Agri. Sci. Tech. 17:1685-1694.

Angulo, F. J.,J.T. LeJeune and P.J. Rajala-Schultz. 2009. Unpasteurized milk: a continued public health threat. World J. Clin. Infect. Dis. 48:93-100.

Ashfaq, M., A. Razzaq and S. Hassan. 2015. Factors affecting the economic losses due to livestock diseases: A case study of district Faisalabad. Pak. J. Agri. Sci. 52:503508.

Butt, A. N. 2020. Available online with updates at https://nation.com.pk/19-Jun-2019/milk-safety-agrowing-health-concern. Accessed on. 20.06.2020.

FAO. 2018. Pakistan's $1^{\text {st }}$ Online Dairy Farming Guide, Introduction, Pakistan. Available online with updates at http://www.fao.org/dairy-productionproducts/products/milk-composition/en/.Accessed on. 14-04-2020. 
GOP. 2019. Pakistan Economic Survey 2018-19, Finance and Economic Affairs Division, Ministry of Finance, Govt. of Pakistan, Islamabad, Pakistan.

Higher Education Commission, Islamabad. 2020. Comprehensive HEC policy/guidelines for universities and DAIs on covid-19. Available online with updates at https://www.hec.gov.pk/english/ HEC Annoucements/ Documents/nCoVirus.HEC-Policy-GuidelinesUniversity. Accessed. 20.06.2020.

Mariam, 2020. Difference between Sterilization and Pasteurization.Online availablewithupdates athttp://www.differencebetween.net/science/differencebetween-sterilization-and-pasteurization/accessed .05.03.2020.

Nayga Jr, R. M., R. Woodward and W. Aiew. 2006. Willingness to pay for reduced risk of foodborne illness:a non-hypothetical field experiment. Can. J. Agri. Econ. 54:461-475.

Paternoster, R., R. Brame, P. Mazerolle and A. Piquero. 1998. Using the correct statistical test for the equality of regression coefficients. J. Crim. 36:859-866.

Punjab Food Authority. 2019. Punjab to ban sale of unpackaged milk from 2020.

Availableonlinewithupdatesathttps://www.thenews.com. $\mathrm{pk} /$ print/545268-punjab-to-ban-sale-of-unpackagedmilk-from-2020. Accessed on 16.06.2020.

Punjab Livestock and Dairy Development Board.2020. Punjab pure milk. Available online with updates athttps://www.plddb.pk/punjab-pure- milk/.Accessed on 12.07.2020

Siddique, M. I. 2018. Microbiological Evaluation of pasteurized milk obtained from different species (cow, buffalo, goat and camel) during storage. M Sc. Inst. Food Sci. Tech.,Univ. Agri., Faisalabad.

Tanvir, A. 2007.A case study of milk production and marketing by small and medium scale contract farmers of Haleeb Foods Ltd. University of Agriculture, Faisalabad, Pakistan. Regoverning Markets Small-scale producers in modern agrifood markets. Available online with updates at https://pubs.iied.org/pdfs/G03258.pdf.Accessed on 17-02-2020

Tanveer, S. 2015. An evaluation of factors that motivate the milk consumers in Pakistan to consume organic milk. UG.diss., Department of Econ., Lahore Univ. Manage. Sci. Lahore, Pakistan.

Van Loo, E. J., V. Caputo, Jr.Nayga, J. F. Meullenetand S.C. Ricke. 2011. Consumers'willingness to pay fororganic chicken breast: Evidence from choice experiment. J. Food Qual. Prefer. 22:603-613.

Vinola, R.,R. Swaminatha and E. Jeevithan. 2018. Current status and comparative study on the influences of cattle packed and unpacked milk in Tamil Nadu: A detailed survey. Research and Reviews: J. D. Sci. and Tech. 4: 6-11.

Zia, M. 2016. Consumer of Processed Food in India:Barriers and Possibilities. J. Agri. Eng. And F. Tech.3:285-290. 